\title{
Reimagining Refugee Identity Systems: A sociological approach
}

\author{
Shirin Madon ${ }^{1} \&$ Emrys Schoemaker ${ }^{2}$ \\ ${ }^{1}$ London School of Economics \& Political Science (madon@1se.ac.uk), ${ }^{2}$ UK \& Caribou Digital, UK
}

\begin{abstract}
This paper explores how the social identity of refugees shapes and is shaped through the process of registering with humanitarian organisations. Building on the recent advance of critical studies on digital identity systems for refugee management, we show how the lens of social identity is helpful in understanding the relationship between refugee information systems and refugee experiences of registration and accessing services. Identity is a key issue related to contemporary information systems yet remains an under-theorised area of investigation from a sociological perspective in the field of information systems, international development and refugee studies. Using qualitative data from 75 refugees in Bidi Bidi refugee camp in Northern Uganda, this paper showcases the centrality of refugees' social identity in determining the journey of vulnerable individuals focusing on three key dimensions. First, how the identities of refugees based on home and family in South Sudan were carried over to refugees' new location in Uganda and were later transformed through the process of registration. Second, how work and career profile of their lives in South Sudan shaped the identity of refugees, and how the absence of education credentials limited the realisation of personal aspirations. Third, how interactions between institutions and refugees are both shaped by and shape refugee identity. Our findings point to important policy implications for designing and implementing refugee identity systems.
\end{abstract}

\section{Introduction}

Refugees are often seen as people who have lost what many regard as the most important form of identity - legal identification by the state. The right to recognise identity has long been an element in the human rights agenda but only relatively recently been identified as a development priority with the adoption of the SDGs in 2015 [25], and its more recent incorporation in SDG 16.9 by 2030 to provide legal identity for all including free birth registration. The loss of legal identity amongst the growing number of refugee communities around the world and their broader vulnerability has led many to explore how new forms of digital technology can empower and protect some of the most vulnerable populations in the world $[26,9,19]$. With its unique mandate for protecting refugees, UNHCR's registration database system called ProGres has become the de facto means of registering refugees [25].

UNHCR defines registration as 'the process of recording, verifying and updating information on persons of concern to UNHCR'. In the initial stages of registration, basic household data is first collected for demographic estimates, followed by data collection to support basic planning and monitoring activities - here additional individual data is collected including sex; date of birth; current location; place of origin (address); date of arrival; special protection and assistance needs; marital status; citizenship; education level; occupation/skills; religion; ethnic origin (tribes/clans/sub-clans); photograph; biometric data if needed and crucially, permission to share information with other parties. However, this detailed personal information is still not sufficient for UNHCR to determine the legal status of individuals. For this, further personal information including names of spouse(s) father and mother; names of all children; place of birth; existing personal documents; documentation issued locally; property status in country of origin; voluntary repatriation status and intentions; resettlement case status; local settlement status; reasons for flight. In sum, extensive personal information is required for UNHCR to determine the legal identity of individuals. Over the years, acceptance of ProGres has grown and by the end of 2010 it had been deployed in more than 250 locations in 82 countries. The system has been updated, to include a suite of modular applications including Rapid Application (RApp) - which allows an offline data collection of refugees (later uploaded to proGres), 
IDPs, and others; CashAssist - that enables registered refugees to receive cash assistance and GDT or Global Distribution Tool, allowing registered refugees to receive in-kind assistance (food, NFI, etc.). UNHCR has also adopted an integrated approach to data collection, which they call PRIMES (Population Registration and Identity Management EcoSystem). This includes all interoperable registration, identity management and caseload management tools and applications, and enables a centralised analytics platform, the PRIMES Dataport, which is accessed through a secure data interface ${ }^{1}$.

Views differ on the gains and risks of digital identity systems for refugees. On the one hand, formal recognition of an individual's legal status as a refugee enables rights and protections whilst the identification systems that deliver this can also help build state capacity to deliver public services and social protection programmes more effectively [18]. On the other hand, concerns related to biometric information are linked to political context. In particular, security perspectives focused on migration and terrorism influence government approaches to biometric identification often conflicting with human rights protection for refugees [16] and biometric use often occurs in contexts lacking data protection legislation [13]. Over the past 10 years, UNHCR has developed a strong data protection policy regarding sharing personal data with governments [25] and other humanitarian organisations have followed suit. However, these policies have proved to be insufficient to ensure privacy and security of refugees. For example, a 2016 audit found that several organisations had limited knowledge of the data protection policy and considered it abstract and difficult to implement due to lack of staff with sufficient technical capacity and political sensitivity [20]. The systems themselves are also vulnerable, with incidences such as World Food Programme's data base breach highlighting how even well-funded systems can be compromised [12].

A key tension for the sector arises between adhering to privacy and data protection laws, and service provision. In low income countries where the majority of refugees are found, the UNHCR typically serves as the response coordinator during the registration process and needs to work together with other partner organisations. The effectiveness of interorganisational data sharing required for coordinated refugee care in turn depends on the data management practices and culture of partner organisations [18]. For example, the ProGres system holds each refugee's unique identity number as well as demographic information which provides a powerful platform for data sharing with service providers. However, many organisations continue to share information via spreadsheets raising concerns over data privacy and security, which has prompted UNHCR and its regional partners in the Middle East to create the Refugee Assistance Information System (RAIS) a web-based regional platform designed to support UNHCR in accessing partner data. In addition to the technological challenge of developing and implementing systems in complex operating environments, the static nature of identities created by organisations to categorise and manage refugees is at odds with the ongoing, dynamic nature of the identity and social life of refugees. One of the key areas for further investigation which we take up in this paper relates to the experience of identity formation by refugees and organisations that work to support them as a result of digital identity systems [18]. In the next section, we commence by unpacking the concept of identity which is intrinsically linked to issues of power, value systems and ideology and which manifests itself through interaction with others.

\section{Conceptualising Digital Identity Systems for Refugee Management}

\footnotetext{
${ }^{1}$ https://www.unhcr.org/3f8e96a04.pdf https://www.unhcr.org/blogs/wp-content/uploads/sites/48/2018/03/2018-03-16-PRIMES-Flyer.pdf
} 
Identity and identification are central concerns of the modern state and bureaucratic systems. Managing, labelling and categorising individuals have long been described as central to the way the state sees and manages the complex social world [22]. The increased prevalence of cross-border movement makes the ability to recognise legal identity even more important and identity management systems have played a key role in many strategic applications including e-governance, e-commerce, business intelligence and homeland security [8]. The focus of advanced technical research on developing open standards that address interoperability, management of privacy and identity theft prevention [10]. On the social side, there have been claims that automation of the citizen-state interface can rebuild trust although the dangers of identity theft or fraud and possible threats to the privacy of individuals resulting from use of these systems have been recognised [6].

For social scientists the main question has been to improve understanding of what exactly constitutes identity and it is this literature that forms the backdrop for our investigation of digital identity systems for refugee management. The concept of identity has been employed to wide purpose across the social sciences, leading some to claim that as a broad term it is tasked with doing too much and as a result achieves too little [4]. An important distinction is between personal identity, taken to refer to something that individuates us while social identity is seen as an individual's awareness of and affiliations with social groups [28,23]. A sociological approach to identity assumes that personal and social identity are related through the concepts of 'sameness' and 'difference'. For example, we are the same human beings and therefore identical with ourselves from birth to death and at the same time share common identities as men, women, refugees, etc. An individual influences society through his or her actions thereby creating categories, groups, networks and institutions while society affects individuals through its shared language and norms [7]. This social interaction often takes on a functional role as one's degree of affiliation with an organisation is assumed to yield important organisational outcomes such as performance [11]. At the same time, we identify ourselves with more than one identity which interact with each other, sometimes in tension [17]. For example, I may ascribe to one common identification category such as a woman but I may dis-identify from certain features of that category such as women's role in marriage or affiliate myself with a certain type of woman.

While many studies of identity adopt a fairly static view of individual perceptions of self and organisational affiliation, a more sociological perspective sees identity as produced and embedded in social relationships and worked out in the practice of people's everyday lives [17]. This perspective rejects an account of refugees as passive recipients of aid but rather agents who seek to re-establish themselves often at the earliest opportunity [3]. Identity is thus seen as something dynamic, acontinuous process of reformulation based on circumstances that vary over time and according to context. Others have described the complex interaction between social identities and the navigation of institutional labelling and categorisation of refugees and the way refugee communities navigate their lives [14]. For example, studies have described refugee agency in terms of the use of mobile phones for interpersonal communication and social networking amongst refugee communities [4]. Beyond interpersonal communication, studies have shown how ICT use enables refugee communities to exercise agency which contributes to their social inclusion into the host community [2]. Increasing demands for securitization of aid and adherence to privacy guidelines in handling personal data have led to humanitarian organisations and state governments placing more importance on identity in terms of biometric and genetic determination obscuring its social character. This is in contrast with sociological perspectives that emphasise the temporal constitution of identity through the narratives people use to make sense of and explain their lives [17] and the role of context, such as social,familial, and historical geographical locations in the formation of identity. For refugees, the role of home is dislocated, as they are forced to abandon their homes, possessions and loved ones, leading to an emphasis on social practices and roles over locations in the determination of identity [24]. 
As the discussion above suggests, refugee identities are complex as they are formed by social affiliations, feelings, beliefs, ethnic and cultural traditions. Moreover, there are external factors such as resettlement practices, policies and the overall socio-economic and political context of the country of origin and host country which affect how identities are shaped. While identity is a profoundly social construct, expert knowledge and administrative processes produce categories and ultimately governance of refugees which get enshrined into systems by the ever-increasing sophistication of new technologies. The poor and dispossessed are often denied a right to negotiate an identity through social affiliations. On the contrary an identity is imposed on them with no official space where this can be contested or where a different identity affirmed. Ultimately, as Sen [23] argues, it is the privileging of discrete data stored in identity systems over the complex and emergent transformation process that leads to 'an epistemic failure in understanding the nature of social identity and its plural aspects'. In this paper, we aim to shed light on how UNHCR's digital identity systems affect the social identities of South Sudanese refugees in the host country of Uganda focusing on three aspects of refugee identity formation: (a) how refugee identity is shaped by home and familial environment, (b) how refugees form identity through work and affiliations, and (c) how identity is created by refugees through their active efforts to forge new affiliations with social protection and service delivery organisations. In the next section, we describe our methodology which is followed by the presentation of empirical findings through stages of transformation in the lived experience of refugees from the time they flee their home, to the granting of refugee status, to the process of integrating within the host country [8]. The discussion and conclusion section draw on implications of our study for theory and practice.

\section{Methodology}

This paper draws on primary data collected by a team of researchers from Caribou Digital over a 9month period from January to May 2018. Although the study involved interviews and focus group discussions (FGDs) in Lebanon, Jordan and Uganda, in this paper we draw exclusively on data from Uganda which has one of the most progressive policies towards refugees with the granting of legal recognition and household ownership of a small parcel of land. The Ugandan government, through its Office of the Prime Minister (OPM), has taken the lead in the registration and management of refugee data [21]. In February 2018, there were over 1.4 million refugees and asylum seekers in Uganda, 21\% of which were in Yumbe which is the locality of the Bidi Bidi camp where we based our study [27]. The recruitment of participant refugees for the study took place through a combination of invitation by partner organizations, personal networks, and snowball sampling. Save the Children, an international NGO, provided logistical and initial recruitment support, inviting beneficiaries to participate in our study. We also drew on our research assistants' personal networks to access community-based organizations active in supporting refugees. Table 1 shows the details of interviews held with refugees and local community members.

Table 1: Details of Interviews with refugees/local community members

\begin{tabular}{|l|l|}
\hline Respondent(s) & Type of interview \\
\hline Former Governor \& education minister in South Sudan & individual \\
\hline Male refugees (16) & individual \\
\hline Female refugee (17) & individual \\
\hline Local Ugandan builder and mobile operator & individual \\
\hline Ugandan Chairperson of Oruba parish & individual \\
\hline Refugee businessman & individual \\
\hline Refugee food distribution volunteer & individual \\
\hline Ugandan local businessman & interview \\
\hline Ugandan local business woman & interview \\
\hline Female refugee with sick child (2) & interview \\
\hline Sick refugee & interview \\
\hline Senior nurse, Bidi Bidi Health Centre 3 & interview \\
\hline
\end{tabular}




\begin{tabular}{|l|l|}
\hline Data Officer, Bidi Bidi Health Centre & interview \\
\hline Ugandan businessman who sells phones and accessories & interview \\
\hline
\end{tabular}

\section{Findings}

Civil war in South Sudan started in 2013 but the majority of refugees arrived in 2016 after which it became increasingly difficult for civilians to escape. Through their narratives, we describe how identities of refugees were configured over time at different stages of their journey in the next three sections.

(i) Refugees' perceptions of their identity from the moment they flee home in South Sudan In 2011, although some people possessed some official forms of ID such as driving license, office ID cards, birth certificate, academic and employment documents and passports, it was only when nearly four million South Sudanese voted in a national referendum for independence from Sudan that the majority became familiar with the national ID card, going on to use it as the main form of identification for employment, receive salary, buy a SIM card, and travel. So when refugees arrived in Uganda, some had ID documents, but many fled with no, few or only the national ID"

'I had my education certificates in South Sudan but lost it due to fighting. They took all my certificates. We lost everything, even our clothes' (FGD Male Dinka Refugees)

Aside from formal credentials, identity for many fleeing refugees also found expression through the affiliation they had back in South Sudan, ,

'I am a theologian. Before becoming a politician, I was a pastor and knew how to counsel myself' (Former Governor \& Education Minister in South Sudan)'

'I was the Chairperson of the Village before becoming part of the Refugee Mobilisation Committee in Bidi Bidi camp' (FGD Male Refugees Bidi Bidi, Zone 1)

Respondents also described how these social identities were legible to others even when efforts are made to disguise it:

'Your name reveals what tribe you belong to but even if you change your name, you can hear the language spoken and tell by looks and lifestyle who is a Dinka, Bantu, Nuer' (FGD with Male Dinka refugees in Bidi Bidi camp)

Part of the identity of all refugees interviewed was shaped by the perilous and hugely political experience they endured to flee from their homes,

'Coming from our village in South Sudan to the border took 3 months moving in the bush and hiding from rebels' (Female Refugee travelling with sick children).

'When you met soldiers or rebels in South Sudan during fleeing and you were asked where you came from and the exact territory, if the governor of the region didn't support your locality, they would be hard on you' (FGD with Male Dinka refugees)

'Sometimes not having your ID was a good think as you didn't want to reveal who you are if you were crossing into Uganda. If you had a Muslim surname, they would restrict you and ask several questions' (FGD Bidi Bidi camp female refugees)

(ii) Refugees' perception of identity as they are granted refuge in Uganda While in South Sudan, the National ID was an important document for proving identity, when fleeing refugees arrived at the border with Uganda, various new forms of identification became important, 
'At the border, UNHCR asked where we came from and issued a wrist band as a form of identification tied to our hand but didn't give us an ID number. They took us by bus to where you will sleep. The next morning, we were taken by bus to the reception centre where they checked our wrist band. Our names were sent from the border to the camp. Later at the camp, there was a word of welcome from OPM, an introduction, and a ration card for immediate food. The attestation card came later' (Individual Male Refugee, Pastor)

For most of the refugees that we spoke to, the importance of identity credentials was directly linked to the benefits they enabled access to. So for example many described how the attestation card issued by the OPM in Uganda enabled access to vital services,

'The attestation card is the most important document for us in Uganda because it proves you are a refugee and it is needed for getting a ration card, for going to hospital or for any activity outside the camp. If you lose your attestation card, it is a lengthy process to get a new one taking 1-2 weeks' (Interview with Dinka refugee women)

'ID documents are my farm. They can feed me, employ me. I struggled for them. When we go back to South Sudan, they will help us get a job' (FGD, Male Refugees, Zone 1)

Refugees also described how in order to obtain a registration credential they had to go through long and complex processes and share very sensitive personal information with registration authorities, questions that exposed various different dimensions of identity of refugees,

'OPM asked questions like your name, your father's name, age, religion, tribe, your place of origin and the route you took to arrive in Uganda. Questions were also asked about hygiene, bodyweight, health leading to immunization by UNHCR, Red Cross, Plan, WFP WV and others. If you didn't answer what they asked you, you were not registered. The whole process took 2-3 days and they sent you to so many places that some people got tired and just left the entire process and didn't get registered' (FGD Male and Female Refugees, Bidi Bidi)

For some refugees, it was not clear why they were asked some questions, including ones that added to their trauma,

'They asked me how many people I had lost so far due to the war. I had lost my husband and it felt that my husband was a number. The day he was shot he was not even carried - we actually left him there' (Female Refugee with sick children)

'Some of us witnessed our parents being killed and they ask us why we are registering alone, where are our parents - you feel like crying' (FGD Male Dinka Refugee)

On the other hand, some refugees commented that they were not asked about issues they felt were were important,

'Some questions which should have been asked were not asked. For example, I came alone from South Sudan and left my husband behind. They didn't ask where by husband was although I was pregnant. They didn't advise me to go to the protection desk that was managed by ARC. They just let me line up' (Female Refugee FGD, Bidi Bidi Camp, Zone 5)

While the majority of refugees interviewed were registered upon arrival, some were not,

'I came from South Sudan and crossed the border but nobody registered me. I just entered. I went to Arua and stayed there with my family for many weeks. Last week I came down to Bidi Bidi but when I arrived nobody registered me. I live with my sister in the camp' (Interview with Unregistered Female Refugee)

'I stay with my son and family but am not registered. The food I am eating is therefore shared with my son and his family as I don't get my own rations' (Interview with unregistered elderly male refugee)

'I came with my brother's 5 children but they didn't ask me about them during registration. Their parents ran away during the war so they were left alone. I came with them to Uganda. They registered them with me together in one card but since then nothing has been done by any organisation to find the parents. IRC and STC have helped us. If a child is sick, you take him to the health centre and they give drugs. But more than anything, my neighbours help me' (Female Refugees FGD Bibi Bidi camp, Zone 5) 
(iii) Refugees' perception of identity as they integrate with the host community and avail of services in Uganda

Various partner organisations operate in Bidi Bidi camp offering services such as employment, healthcare and ration to refugees of which $30 \%$ go to the host community. Adverts for jobs were typically posted on trees inside the camp. Some refugees were successful in obtaining a job. For example, one refugee was working as Secretary for Child Welfare,

'We used to organise meetings for women so that we would know their position. One woman thought she was HIV positive but feared going to the health centre. I used to go to her house to counsel her and personally escorted her to the health centre where she was found HIV positive. I was with her every step until she was treated and I went to the complaint desk so that she could get more assistance as she had no house or husband' (Interview with Dinka Refugee Woman)

\section{Another refugee secured work as a volunteer with World Vision,}

'We help people calculate their food ration and direct people to the complaint desk if they have lost their ration card. The complaint desk verifies their name on the computer and gives them a chit enabling them to obtain their ration. We also organise queues with special ones for persons with special needs and ensure that the whole process of food distribution runs smoothly and people are not taking more than their quota' (Interview with Refugee Food Distribution Volunteer, Bidi Bidi, Zone 5)

Some refugees started their own business,

'I am a refugee and began my small business of selling biscuits, sugar, coffee, matchbox, fish, eggs, SIM and cigarettes for cash. I buy from traders in the centre. I started by business by keeping $2 \mathrm{~kg}$. of corn back from my ration every month. This helped to start my business because corn doesn't go bad' (Refugee Businessman, Bidi Bidi)

Another of the Dinka women interviewed explained the relevance of partner organisations employing refugees in curbing domestic violence against women. Violence was often inflicted by male refugees who had arrived later than their wives and had consequently had become registered as head of household with control of household resources ,

'Every month in coordination meetings, all the partners working in Zone 1 including UNHCR and OPM will be there and we discuss al the issues. If cases are urgent such as domestic violence we go to the Chairman and complain and go to the police if the violence is too bad, otherwise the Chairman will resolve' (Interview with Dinka Refugee Woman)

Some refugees encountered difficulties in securing a livelihood,

'I arrived in Bidi Bidi in 2016 with my children. My husband is still in South Sudan. It is not easy to secure a livelihood by cultivating crops as there is no place to cultivate' (Individual Female Refugee Community Activist)

'If you have the academic diploma to show that you have the skills for the job, or a document to say you have gained experience then you have a chance. But if you have no documents and you see an advert and apply, they will not trust you and don't care if you had to flee and didn't have time to get your documents' (FGD Male Refugee, Zone 1)

In some cases, refugees felt that despite collecting data from them, NGOs providing services did not fully understand what they want, and seemed to use the information for their own purposes:

'They seldom interact with refugees - they should come down to ground level to get people's ideas about what we are suffering from. They should reach out to our leaders like the Refugee Welfare Council to discuss our issues and what we need from these organisations. Instead they come with their own ideas like training our children in tailoring skills. We would rather they have an education which is something more permanent'. (Individual Female Refugee Community Activist) 
The loss of education credentials surfaced as a key dimension affecting the identity of many of the refugees, particularly those who had previously studied in Uganda but had now become registered as refugees and faced difficulties in furthering their career aspirations. However, despite the fact that Window Trust was the organisation supporting education within Bidi Bidi camp and coordinated with UNHCR, there were several factors that prevented refugees from continuing their education,

'I had my certificates in South Sudan but lost them due to fighting. They took my certificates - all of them. When we came here they tell us that if we have nothing to show that you have been to secondary school you have to start again from primary school. This discouraged us from going for further studies' (FGD with Male Dinka Refugees)

'While many refugees came to Uganda with school testimonials to certify that they had passed their exams, Ugandan authorities insisted on original documentation. It was also difficult to convert South Sudanese P8 certificate to Ugandan P7 and some refugees dropped out of school because of that' (FGD with 7 Female Refugee Students)

In addition to the credentials needed to access education, many described difficulties around the use of credentials to access food rations. World Vision was responsible for providing rations in the camp, and used a megaphone to announce when food distribution would occur. Distribution protocols made it mandatory that the ration can only be collected by an individual named on the card,

'For ration collection, before if you are not around to collect your food someone could get it for you using the ration card, but now they want the real person. This is bad because if the owner of the ration card has gone to the clinic, you will not get the food' (FGD Male Refugee, Zone 1)

There has been growing trend among donor agencies to replace ration distribution with cash transfer direct to refugees although our interviews showed that this was not desired,

'Money is nothing to us here. Food is more important than money. Men would say yes because they are drunkards and would use the money for drinking alcohol and smoking. They don't mind if the children eat or not. In South Sudan, people would prefer money than here in the camp because both ladies and husbands were working but in Yumbe district there is food starvation. Even if we had money, we would wonder where to buy food from' (Interview with Dinka women)

We also heard even after being identified as people with special needs, some respondents reported how services never arrived. According to protocols in place, PSN refugees were identified by CRS for special assistance. However, in practice, this assistance was not forthcoming,

'CRS were moving from house to house to identify PSN refugees and the Chairman directed them to us. They promised to construct latrines and build houses but since that time they never came back (FGD with Female Refugee, Bidi Bidi, Zone 5)

Respondents described agency and independence as one of the biggest differences between their life before and their life since becoming a refugee. Overall, refugees felt that their living conditions in the host country were far more difficult than in South Sudan,

'In South Sudan, we had our own food and we could cultivate for ourselves and could get ourselves tested at the health centre. But here there is no food, medicines or land' (Unregistered Elderly Male Refugee)

'I was working for Voices for Change in South Sudan. I was taking care of myself and could easily get everything I wanted. Here I am not working and depend on rations and if I sell some of it, it wont be enough, so living is more difficult here than in South Sudan' (FGD Female Refugee, Bidi Bidi, Zone 5)

Feelings appeared mixed among refugees about how their new environment affected their political allegiances,

'There is a lot of debate amongst the South Sudanese which takes place on forums like FB and WhatsApp. We have our own intellectual think tank group of 1-8 and we have a platform where we share and debate issues on 
South Sudan, especially the current negotiations in Ethiopia' (Former Governor \& Education Minister in South Sudan)

On the other hand, some refugees were more cautious about maintaining political affiliations,

'For me, the topic I don't talk about is politics because it is what caused us problems and made us refugees. Sometimes I feel that if I engage in such talk, someone might just come and attack me' (FGD Male Refugee, Bidi Bidi, Zone 1

'I am not a rebel, but because I am no longer in my country I am regarded as non-aligned with the South Sudanese government and they would accuse me of being a rebel' (Former Governor \& Education Minister in South Sudan)

Despite being united with others in the broader identity category of being a refugee, social identities such as political and ethnic affiliation remained as markers of difference amongst refugees,

'There are some tribes from South Sudan who hate us because they think that it is us who brought the war. The problem arose where tribes were mixed up in the camp. Now OPM is protecting the Dinka community by organising dialogues between all the refugees and the host community' (Interview with Dinka women)

\section{Discussion and Conclusion}

In this paper, our main contribution has been to provide theoretical insights into the functioning of social identity as it applies to refugees from South Sudan who had to flee their country due to civil war and who have tried to reconstruct their lives and identities in the host country of Uganda. Our first analytical category related to how refugee identity relates to home and familial surroundings. Most refugees we studied experienced an abrupt and traumatic escape from violence. Together with leaving behind formal identification documents, the social bonds and cultural norms that the refugees had built up over time in their home country were disrupted. As refugees began the long process of registering their status as formal refugees in Uganda, their legal identity was transformed as a result of their new status as refugees and the attestation card which was important in helping them secure food and other services. We found that the registration process was often stressful with questions asked by UNHCR and other organisations to satisfy their internal administrative and assessment needs often forcing refugees to relive the experiences of fleeing their homes and familial surroundings. For those refugees unable to register, their lack of formal status affected their ability to reconstruct a sense of 'home' in the host country. In some cases, our findings showed that identity reformulation for refugees was a constructive, positive process. For example, Ugandan respondents described in positive terms how the presence of refugees had improved their own life conditions creating a bond of reciprocity through the exchange of basic commodities. Even so, identity formation for registered refugees in Uganda has been a difficult process as living conditions were found to be far more difficult for them compared to their lives and surroundings back home in South Sudan. Moreover, differences in tribal identity, for example between Dinka and refugees from other ethnic groups with histories of ethnic conflict, were seen to carry over into their new habitat. Rather than a unified, single identity as refugees, ethnic tensions and earlier political allegiances came to shape the identity of refugees who fled their country in search of a better life. Finally, UNHCR's registration process restructured traditionally patriarchal families into female headed households thereby restructuring the family unit and enabling women to exercise a form of control over household resources that in their previous, patriarchal context had been impossible. Yet this experience of empowerment has not been without cost, as a number of people in service providing organisations described how the biggest cause of domestic violence was violence arising from men refusing to accept that their wives could make choices about what to do with food items and household resources.

Our second analytical category relates to identity formation through work and career aspirations. The loss of family, homes and possessions was often accompanied by the loss of work and career identity. Many of the refugees we interviewed had held positions of authority in South Sudan and in most 
cases, both men and women within a household would typically work and thereby contribute to the family income. One of the strongest common experiences from our findings was the loss of agency and self-worth as refugees described being unable to work and therefore dependent on others for the most basic everyday necessities. The absence of work opportunities and reliance on outside organisations for such basic requirements as food items reduced individuals sense of professional identity. For the refugees in this situation, in addition to the material benefits afforded by the additional income, obtaining employment was an important aspect of reconstructing a professional identity. Many respondents also described how the lack of education credentials was a significant barrier to opportunity which in turn limited the opportunity to pursue further education and livelihood opportunities as well as to pursue broader hopes for prosperity.

Our third analytical category relates to how refugees negotiate new identity relations through their interactions with organisations that provide protection and basic services to them. Our findings showed that some refugees who possessed educational and employment credentials were able to obtain work with partner organisations and thereby build bridges with the local community. However, most of the refugees we interviewed felt that implementing organisations had little understanding of their needs and, despite the use of digital identity systems, some refugees lack credentials and were unable to develop links with service organisations. There were also tensions between the criteria that different organisations placed on the delivery of services. For example, if refugees were unable to present themselves on the day and time of ration distribution, or to present their identity credentials, they were unable to obtain food and other items that they needed.

Our analysis of refugee identity from a sociological standpoint has important implications for policy. At a time when increasing focus is placed on data-driven solutions to managing refugees, a social perspective reminds us that identities are ultimately produced and reproduced through the lived reality of individuals. Our findings show that there are numerous psychological, legal, geographical, economic and social factors that combine to shape the identity of refugees as identified by other scholars.Castro Serrato (2014) describes how rather than credentials, refugees highlighted the distance to facilities, extended waiting periods, privacy concerns, inconsistent quality of service, and staff attitudes towards refugees. Similarly, as [15] report, residents of Dadaab struggle with lack of capital and skills in their reconstruction of work identity. From our study, increasing refugee access to education is shown to be critical in enabling long-term development. Institutional support is needed to help particularly youth refugees to continue their education and develop skills that can help them generate income. Strengthening the portability and interoperability of education credentials would help overcome the challenges faced by individuals who have left their documents behind, and to support the transfer of certificates between differing institutional regimes. The digital identity registration systems of UNHCR and other humanitarian organisations afford very limited opportunities for refugees to exercise control over personal data, to amend or exercise choice over who has access to their personal information, increasing the sense of helplessness amongst already very vulnerable populations. Together with the sharing of personal information is shared without their knowledge or agreement, this poses issues around personal privacy, security and safety from oppressive regimes and fundamental human dignity. Enabling greater refugee agency over the management and distribution of entitlements would make it easier for individuals with complex lives to access services and welfare as well as to increase the effectiveness of delivery. In the absence of this type of measure, many refugees who are already vulnerable due to health ailments they suffer from or because of sick children fall further behind in terms of reconstructing their lives. Strengthening refugee identity management systems introduces wider developmental issues that need to be faced, as these systems always interact with other national identification systems, which have to be strengthened if the interaction is to be meaningful.

To conclude, increasing focus is being placed on data-driven solutions to refugee management in international public policy discourse. However, while new technologies have a role to play in 
increasing efficiency and effectiveness, can refugee identity be managed through a technical system alone? While the affordances of technology facilitate the linking of biometric identity systems with cash transfer mechanisms for refugees, the ground level realities suggest that caution is exercised before introducing new ways of delivering aid to refugees. In Bidi Bidi camp, we saw how limited mobile network coverage reduced the utility of mobile based service provision, with many 'dead spots' without any access to mobile network reception. Furthermore, we also heard how the absence of markets limited the utility of digital cash transfers. Ultimately, our research in Uganda highlights how technological systems and institutional efforts to make humans legible require further understanding of their interaction with the lived experiences and social identities of refugees in order to help develop context specific responses to the needs of vulnerable refugee populations.

\section{References}

1.Andrade AD, Doolin B (2016) Information and Communication Technology and the Social Inclusion of Refugees, MIS Quarterly 40: 405-416. doi: 10.25300/MISQ/2016/40.2.06

2. Benton M, Glennie A (2016) Digital Humanitarianism. How tech entrepreneurs are supporting refugee integration, Migration Policy Institute, Washington DC.

3. Betts A, Bloom L, Kaplan J, Omata N. (2014) Refugee Economies: Rethinking popular assumptions, Humanitarian Innovation Project, Oxford.

4. Brubaker R, Cooper F. (2000) Beyond 'identity.' Theory and Society doi:

10.1023/A:1007068714468

5. Burnett K. (2013) Feeling Like An Outsider: A case study of refugee identity in the Czech Republic, Policy Development and Evaluation Service, United Nations High Commissioner for Refugees, Geneva, Switzerland.

6. Crossman G. (2007) The ID Problem. In Digital Identity Management: Technological, Business and Social Implications, David Birth (ed.), Routledge, Oxon, pp. 175-183. doi:

10.1142/9789812837042_0015

7. Gelb A, Diofasi A (2018) Can Digital ID Be Harnessed For Development? Centre for Global Development, Washington DC.

8. Glasser U, Vajihollahi M (2010) Identity Management Architecture. In Security Informatics, CC. Yang et al. (eds.) Annals of Information Systems 9, Springer Science \& Business Media.

9. GSMA (2017) Refugees and Identity: Considerations for Mobile-Enabled Registration and Aid Delivery | Mobile for Development. GSMA, July 20, 2017.

https://www.gsma.com/mobilefordevelopment/programme/mobile-for-humanitarianinnovation/refugees-and-identity/.

10. Haddouti S, El Kettani M (2015) Towards an Interoperable Identity Management Framework: A comparable study, International Journal of Computer Science Issues, 12: 1694-0784. doi:

10.1016/j.future.2018.09.025

11. Haslam A, Reicher S (2006) Social Identity and the Dynamics of Organisational Life. In Identity and the Modern Organisation, edited by C. Bartel et al., Lawrence Erlbaum, Mahwah, NJ. doi:

10.1111/ijmr.12035

12. IRIN (2018) Exclusive: Audit Exposes UN Food Agency's Poor Data-Handling.” IRIN, January

18. https://www.irinnews.org/news/2018/01/18/exclusive-audit-exposes-un-food-agency-s-poor-datahandling.

13. Jacobsen KL (2015) Experimentation in Humanitarian Locations: UNHCR and biometric registration of Afghan refugees, Security Dialogue, 46: 144-164. doi:

org/10.1177/0967010614552545

14. Janmyr M, Mourad, L (2018) Modes of Ordering: Labelling, Classification and Categorization in Lebanon's Refugee Response, Journal of Refugee Studies, doi.org/10.1093/jrs/fex042.

15. Kamau C, Fox J (2013) The Dadaab Dilemma: A study on livelihood activities and opportunities for Dadaab refugees, DRC/UNHCR Nairobi.

16. Kingston L (2018) Biometric Identification, Displacement, and Protection Gaps. In Digital

Lifeline? ICTs for refugees and displaced persons, edited by Carleen Maitland, MIT Press,

Cambridge MA., pp. 35-55.

17. Lawler S (2014) Identity: Sociological Perspectives, Polity Press, Cambridge. 
18. Maitland. C (2018) Information Systems and Technologies in Refugee Services. In Digital Lifeline? ICTs for refugees and displaced persons, edited by Carleen Maitland, MIT Press, Cambridge MA., pp. 55-79. doi: org/10.7551/mitpress/10843.001.0001.

19. Oakeshott N (2018) Empowering Refugees and Internally Displaced Persons through Digital Identity. Voices, June 19, 2018. http://blogs.worldbank.org/voices/empowering-refugees-andinternally-displaced-persons-through-digital-identity.

20. Office of Internal Oversight Services (2016) Audit of the Biometric Identity Management System at the Office of the United Nations High Commissioner for Refugees, UN, New York.

21. OPM (2018) Office of the Prime Minister. Refugee Management. https://opm.go.ug/refugeesmanagement/

22. Scott J (1998). New Haven: Yale University Press.

23. Sen A (2009) The Fog of Identity, Politics, Philosophy \& Economics, 8:285-288. doi: org/10.1177/1470594X09105388

24. Simich L, Este D, Hamilton H (2010) Meanings of Home and Mental Wellbeing among Sudanese Refugees in Canada, Ethnicity and Health, 15: 199-212. Doi: org/10.1080/13557851003615560

25. UNHCR (2015) Policy on the Protection of Personal Data of Persons of Concern to UNHCR, UNHCR. Geneva.

26. UNHCR (2017) Opportunities in the New Digital Age - UNHCR Blog. October 26, 2017. http://www.unhcr.org/blogs/opportunities-in-the-new-digital-age/. http://www.unhcr.org/blogs/opportunities-in-the-new-digital-age/.

27. UNHCR (2018) Uganda. https://data2.unhcr.org/en/country/uga

28. Van Tondler CL (2006) Exploring the Identity and 'Sense of Identity' of Organisations, SA Journal of Industrial Psychology, 32: 12-25. doi:10.4102/sajip.v32i3.433 